\title{
Comparison of Magnesium Olivine Phosphorous Removal Characteristics in Different Temperature Firing
}

\author{
Jingpeng $\mathrm{Li}^{1,2, a}$, Mingzhe Wang ${ }^{2, \mathrm{~b}}$, Yitao $\mathrm{Hu}^{3, \mathrm{c}}$, Jialin Yang ${ }^{4, \mathrm{~d}}, \mathrm{Xu}$ Zaizhou ${ }^{2, \mathrm{e}}$, \\ Tianjiao Luo,
}

${ }^{1}$ Research Center for Eco-Environmental Sciences, Chinese Academy of Sciences, Beijing 100085, China;

${ }^{2}$ Beijing University of Technology, Beijing 100022, China;

${ }^{3}$ Zhengzhou University, Zhengzhou 450001, China;

${ }^{4}$ Beijing Institute of Thehnology, Beijing 100081, China;

${ }^{5}$ The High School Affiliated to Renmin University of China, Beijing 100080, China

acedric_lee@yeah.net, b984138249@qq.com, cpowerfulhu@icloud.com

dcedric_lee@yeah.net, e1120132857@bit.edu.cn, fjj990613@126.com

Keywords: Magnesium olivine, Constructed wetland substrate, Phosphorus removal, Temperature.

\begin{abstract}
As a kind of magnesium rich material, magnesium olivine has been proved to be a kind of artificial wetland substrate, which has a good effect on phosphorus removal. Therefore, it selected firing of the magnesium olivine under the $800^{\circ} \mathrm{C}, 1000^{\circ} \mathrm{C}, 1600^{\circ} \mathrm{C}$ as the research object. The characteristics of phosphorus removal were investigated and compared. The experimental results show that the adsorption isotherm equation of Langmuir can well describe the adsorption process of phosphate on the magnesium olivine at different temperatures. Its phosphate saturated adsorption capacity was $195.65 \mathrm{mg} \cdot \mathrm{kg}^{-1}, 169.49 \mathrm{mg} \cdot \mathrm{kg}^{-1}$ and $145.43 \mathrm{mg} \cdot \mathrm{kg}^{-1}$. At the same time, all kinds of magnesium olivine phosphorus desorption degree is low. It is proved that the performance of the magnesium olivine with low temperature is better. It is more suitable to be used as artificial wetland substrate.
\end{abstract}

\section{Introduction}

Phosphorus is one of the main inducing factors of eutrophication, which is very easy to lead to eutrophication of water. The eutrophication of water will lead to the decrease of water quality and increase of water turbidity, which will affect the photosynthesis of aquatic plants. It leads mass death of aquatic organisms. The eutrophication of the water body will destroy the aquatic ecological balance. Therefore, phosphorus has been regarded as the main content of wastewater treatment.

As a new type of ecological engineering technology, constructed wetland is used to coordinate the principle of species symbiosis, material recycling principle, structure and function. Through a series of physical, chemical and biological pathways of the substrate, aquatic organisms and microorganisms, the depth treatment of the sewage is completed, and the phosphorus in the sewage is excellent. Among them, the deposition and adsorption of the matrix is the main way to remove phosphorus. The contribution rate is as high as $70 \% \sim 87 \%{ }^{[1-5]}$.

Wetland matrix has been recognized as the final destination of phosphorus in wetland system ${ }^{[6]}$. The removal efficiency of phosphorus is closely related to the selection of wetland matrix materials ${ }^{[7-11]} . \mathrm{Al}^{3+}, \mathrm{Fe}^{3+}, \mathrm{Ca}^{2+}$ of the substrate can be achieved by adsorption and precipitation of phosphorus removal efficiency ${ }^{[12]}$. The phosphate in the water has better removal ability ${ }^{[13]}$. Therefore, it is one of the core ideas to select suitable materials for artificial wetland to improve the purification capacity of constructed wetland. In the preliminary study in the laboratory, we found that magnesium olivine has a good effect on phosphorus removal. But the temperature of the firing of the magnesium olivine with the best phosphorus adsorption effect has not yet been directly demonstrated. The purpose of this experiment is that adsorption treatment effect of forsterite by comparing different temperature 
firing phosphorus, demonstrates the burning temperature on the effect of forsterite phosphorus uptake. It can select the best effect of magnesium olivine and provide the basis for selecting suitable artificial wetland substrate.

\section{Material and Methods}

\subsection{Testing instruments and medicines.}

Desktop bed temperature, ultraviolet-visible spectrophotometry meter, $0.45 \mu \mathrm{m}$ membrane, syringes, glassware, $10 \%$ ascorbic acid solution, $1+1$ sulfate, molybdate solution, phosphate standard solution, deionized water.

Magnesium olivine is a kind of magnesium olivine minerals which fired by Yichang Hubei Stone Gold Technology Development Co., Ltd. It is orthorhombic, and the molecular structure of Mg2SiO4 silicate materials. It is rich in $\mathrm{MgO}$, respectively, by $800^{\circ} \mathrm{C}, 1000^{\circ} \mathrm{C}, 1600^{\circ} \mathrm{C}$ calcined. The size of the matrix was $2 \sim 3 \mathrm{~mm}$. The size of the matrix was $2 \sim 3 \mathrm{~mm}$. The magnesium olivine is cleaned with de ionized water and soaked in $12 \mathrm{~h}$ before use it. And then it dried at $105 \mathrm{C}$ after $24 \mathrm{~h}$.

\subsection{Test method.}

\subsubsection{Isothermal adsorption test}

It selected three kinds of matrix $10.0 \mathrm{~g}$ (Set 2 parallel), and putted it in the conical flask with a volume of $250 \mathrm{ml}$. According to the matrix and solution solid-liquid ratio 1:20, respectively added $0.02 \mathrm{~L}-1 \mathrm{KCl}$ mol solution prepared by the different phosphorus concentration (in the $\mathrm{P}$ meter, the same below) of the KH2PO4 standard solution 200mL. Phosphorus concentrations were 1, 2, 5, 10, $20,50,100,200,400 \mathrm{mg} \cdot \mathrm{L}^{-1}$. The tapered bottle is arranged in the thermostatic shaker, in $150 \cdot \mathrm{r} \cdot \mathrm{min}^{-1}$, $(25+5)^{\circ} \mathrm{C}$ under the condition of continuous oscillation $24 \mathrm{~h}$. To determinate the phosphorus concentration in water sample with $0.45 \mu \mathrm{m}$. According to the change of phosphorus concentration, the phosphorus adsorption capacity of matrix was calculated, and the phosphorus adsorption isotherm was drawn.

\subsubsection{Substrate phosphorus release test}

Each of these tests was taken to get the saturated adsorption of phosphorus in the matrix $1 \mathrm{~g}$ (Set 2 parallel), added $0.02 \mathrm{~mol} \cdot \mathrm{L}^{-1} \mathrm{KCl}$ in the solution with $50 \mathrm{~mL}$, and placed in the bed temperature. Continuous oscillation under150r $\cdot \min ^{1}(25+5)^{\circ} \mathrm{C}$. At $30 \mathrm{~min}$ and $1,2,4,6,8,10,12.0 \mathrm{~h}$, respectively taken the amount of supernatant, and analyzed phosphorus concentration after the water sample was $0.45 \mu \mathrm{m}$.

\subsection{Analysis method.}

\subsubsection{Drawing of standard curve}

Taken $50 \mathrm{ml}$ with SEBI color tube, and added to the standard solution phosphate $0,0.50 \mathrm{ml}, 1.00 \mathrm{ml}$, $3.00 \mathrm{ml}, 5.00 \mathrm{ml}, 10.0 \mathrm{ml}, 15.0 \mathrm{ml}$. Deionized water is added to $50 \mathrm{ml}$. Plugged $1 \mathrm{ml}$ ascorbic acid solution with $10 \%$ into color tube. Added $2 \mathrm{ml}$ molybdate solution mixing after $30 \mathrm{~s}$, and placed $15 \mathrm{~min}$. The samples were moved to $10 \mathrm{~mm}$ or $30 \mathrm{~mm}$ color tube, the measurement of absorbance, drawn standard curve at the $700 \mathrm{~nm}$ wave strengths with zero concentration of the solution as the reference.

\subsubsection{Sample determination}

Respectively taken appropriate membrane water (containing less than $30 \mathrm{mu}$ g) in the cuvette, diluted with deionized water to mark. And then, according to the standard curve steps, develop color and measure. Minus blank test absorbance, and find out the phosphorus content from the standard curve.

\subsection{Adsorption equation.}

Langmuir is one of the most commonly used equations to describe the adsorption equilibrium.

$\frac{1}{q_{e}}=\frac{1}{\mathrm{qe}^{*} b^{*} C_{e}}+\frac{1}{q_{m}}$

$\mathrm{q}_{\mathrm{e}}$ is the equilibrium adsorption capacity of adsorbent, $\mathrm{mg} \cdot \mathrm{kg}^{-1} \cdot \mathrm{q}_{\mathrm{m}}$ is the saturated adsorption capacity of adsorbent, $\mathrm{mg} \cdot \mathrm{kg}^{-1} \cdot \mathrm{C}_{\mathrm{e}}$ is the equilibrium concentration, $\mathrm{mg} \cdot \mathrm{L}^{-1} \cdot \mathrm{b}$ is a Langmuir constant. 
Langmuir adsorption isotherm equation is assumed to be uniform, which is mainly used to describe the adsorption of single molecule layer ${ }^{[14]}$.

\section{Discussion and Conclusion}

\subsection{Isothermal adsorption test.}

Through the analysis of different burning temperature of $25^{\circ} \mathrm{C}$ under the condition of forsterite for isothermal adsorption curve and equation of phosphate, we can see from the Fig. 1, Fig. 2 and Fig. 3 that the total amount of phosphorus adsorption on the three substrates showed a positive correlation with the concentration of the solution, and with the same concentration, the total amount of phosphorus adsorption was different between the three different substrates. By means of mathematical fitting, Langmuir adsorption isotherm equation is more suitable for the adsorption of phosphate in water by three kinds of magnesium olivine. The saturated adsorption capacity of the substrate can reflect the purification ability of the substrate to phosphorus, which is an important parameter to select the artificial wetland substrate. According to the Langmuir equation, the three phosphate saturated adsorption capacity was $195.65 \mathrm{mg} \cdot \mathrm{kg}-1,169.49 \mathrm{mg} \mathrm{kg}$ and $145.43 \mathrm{mg} \mathrm{kg}^{-1}$. Theoretical saturation adsorption shows that it is easier to adsorb phosphate in water with low firing temperature.

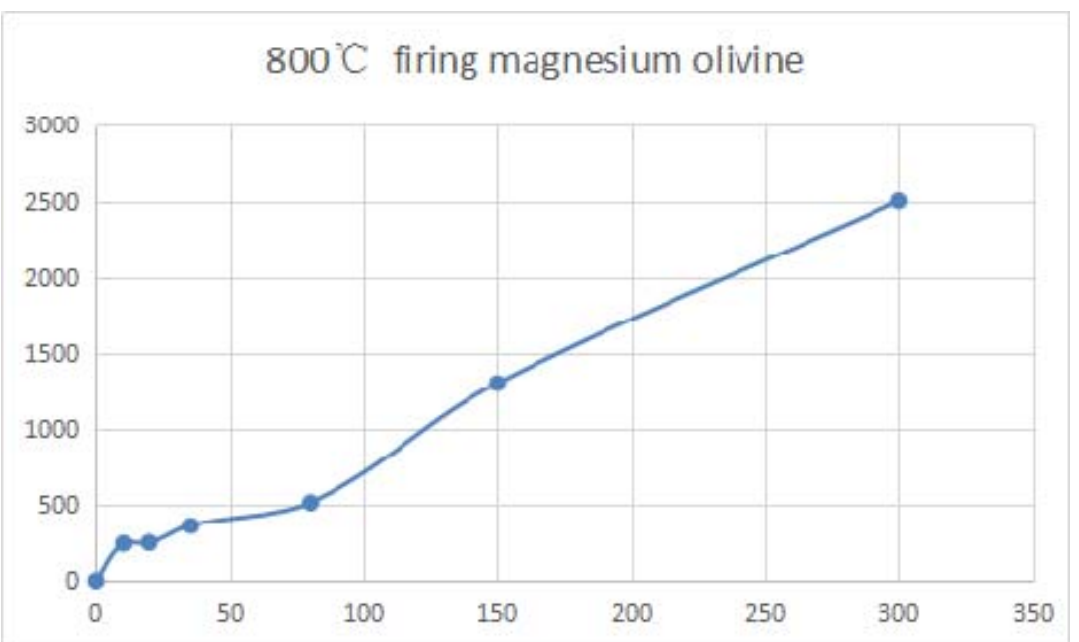

Fig. 1 Adsorption isotherms of phosphorus in aqueous solution of $800^{\circ} \mathrm{C}$

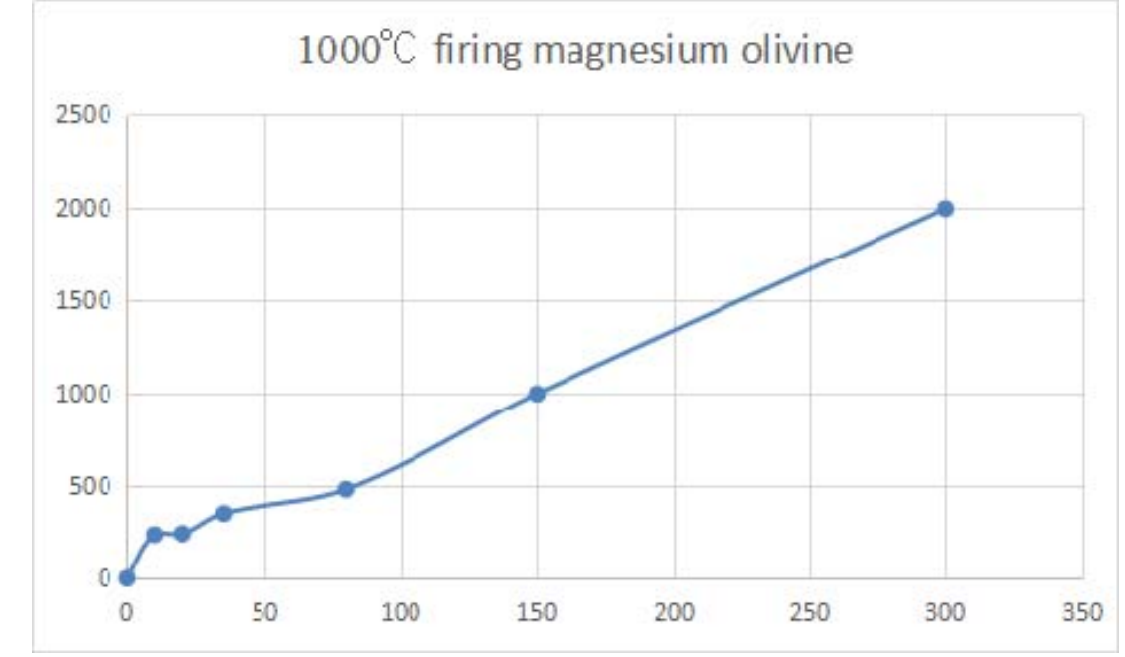

Fig. 2 Adsorption isotherms of phosphorus in aqueous solution of $1000^{\circ} \mathrm{C}$ 


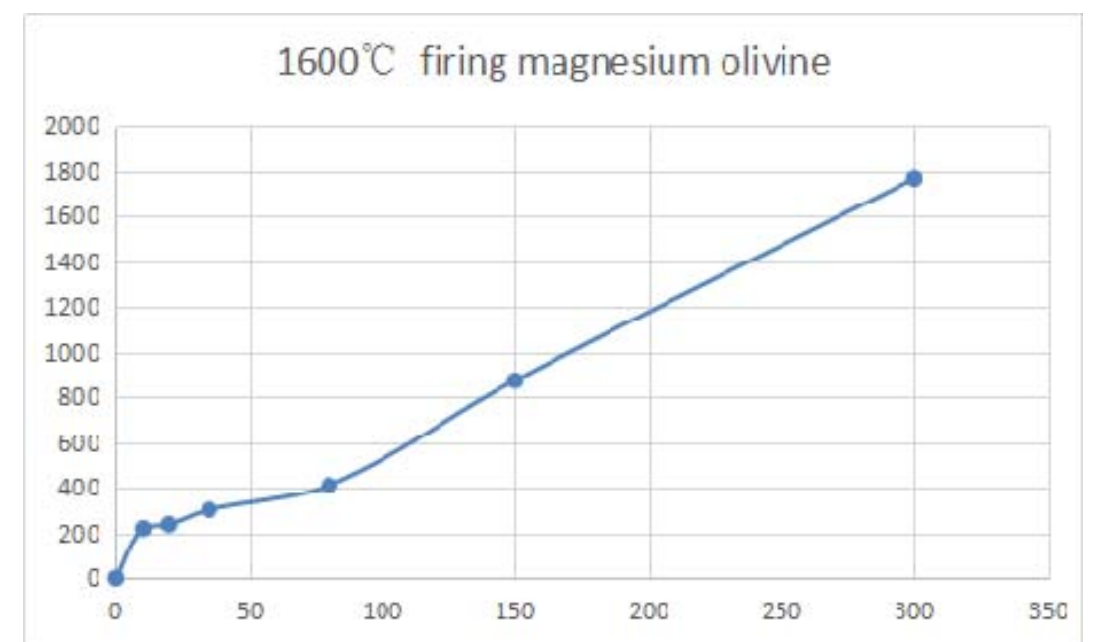

Fig. 3 Adsorption isotherms of phosphorus in aqueous solution of $1600^{\circ} \mathrm{C}$

The horizontal coordinate is the concentration of phosphate balance solution and $\mathrm{mg} / \mathrm{L}^{-1}$; the vertical coordinate is phosphorus adsorption $\mathrm{mg} / \mathrm{kg}^{-1}$.

\subsection{Substrate phosphorus release test.}

As shown in Fig. 4, the liquid solution in the same place, small amount of phosphorus magnesium olivine $12 \mathrm{~h}$, phosphorus release percentage was $11.19 \%$. It can be known that when the magnesium olivine is used as the filler of the artificial wetland, it is less likely to be polluted by two times.

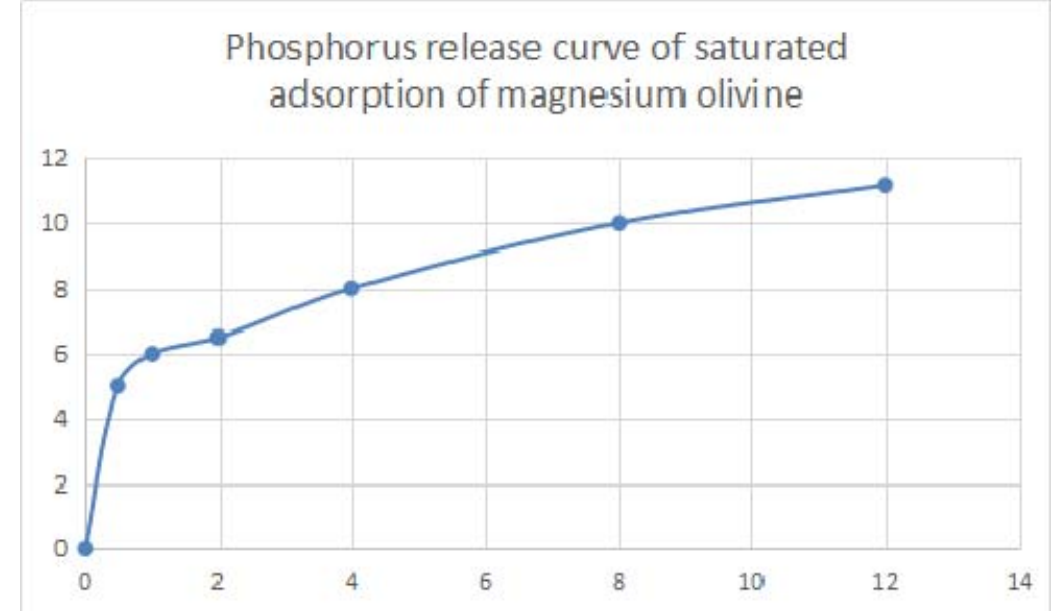

Fig. 4 Phosphorus release curve of saturated adsorption of magnesium olivine

The horizontal coordinates are time/h; the vertical coordinate is the rate of phosphorus release $/ \%$.

\section{Result and Conclusion}

1) The lower the firing temperature, the better the adsorption ability of the magnesium olivine.

2) The release of phosphate from olivine to phosphate is low, and the risk of the second contamination is small.

3) Langmuir adsorption isotherm equation can well describe the phosphate adsorption process of three kinds of magnesium olivine.

\section{References}

[1].Li Zhijie, Sun Jingmei, Liu Baoshan. Mechanism of nitrogen and phosphorus removal in constructed wetland and its research progress [J]. industrial water treatment, 2012,04:1-5.

[2].Strategies, Yu Dawei, Zhengxiang, Wei Yuan. The artificial wetland in urban sewage treatment plant tail water removal of nitrogen and phosphorus in the progress of research and application [J]. Journal of agro environment science, 2012,12:2309-2320. 
[3].Xiong Fei, Li Wenzhao, Pan Jizheng, Li Aiquan, summer Xiang. Research progress on the effect and mechanism of nitrogen and phosphorus removal in constructed wetlands $[\mathrm{J}]$. wetland science, 2005,03:228-234.

[4].Lu Shaoyong, Jin Xc, more than just [J].. The removal mechanism of the wetland ecological environment p, 2006,02:391-396.

[5].PantHK, Reddy K R, Lemon E. Phosphorus retention capacity of root bed media of sub-surface flow constructed wetlands[J]. Ecological Engineering, 2001, 17(4):345-355

[6].Richardson C J. Mechanisms controlling phosphorous retention capacity in fresh-water wetlands[J]. Science, 1985, 228(4706): 1424-1427

[7].Wang Zhen, Liu Chaoxiang, Dong Jian, Liu Lin, Li Pengyu, Zheng Jiayu. Screening and phosphorus removal in Constructed Wetland for phosphorus removal and phosphorus removal [J]. China Environmental Science, 2013,02:227-233.

[8].Zhao Guiyu. Screening and adsorption mechanism of phosphorus removal in constructed wetland [D]. Tongji University, 2007

[9].2009,01:45-48. Li Xiaodong, Shi Xiaochun, Chao Lei and increased. The blast furnace slag substrate in constructed wetland phosphorus removal [J]. Journal of Meteorology and environment.

[10].He Jie. Study on adsorption mechanism of phosphorus and phosphorus in constructed wetland [D]. Wuhan University of Technology, 2014

[11].Teng Lianghui, Zhang Yanyu, Chun Guang he and Sheng Lianxi. Volcanic slag as a comparative study on the removal effect of phosphorus in the substrate of constructed wetlands [J]. Northeast Normal University (NATURAL SCIENCE EDITION), 2015,03:132-136.

[12].Akratos C S, TSsihrintzis V A. Effect of temperature, HRT, vegetation and porous media on removal efficiency of pilot-scale horizontal subsurface flow constructed wetlands[J]. Ecological Engineering, 2007, 29(2): 173-191

[13].Zhang Xuhua, Liu Yong, Qin Jianming, Zhang Xifeng. Study on phosphorus removal from wastewater by Magnesium Oxide [J]. Henan science, 1998,03:53-56.

[14].Trin.ex, Jing Lijie, Gao Shixiang, Yin Daqiang, Wang Liansheng. Different substrates used in constructed wetland phosphorus purification element pollution performance analysis [J]. Environmental science, 2005,01:51-55. 